\title{
Enhanced hydrogen storage performance of reduced graphene oxide hybrids with nickel or its metallic mixtures based on spillover mechanism
}

\author{
Lin Wei, Yuanbing Mao* \\ Department of Chemistry, University of Texas Rio Grande Valley, Edinburg, Texas \\ 78539, USA \\ *To whom correspondence should be addressed: Tel: +1 956665 2417; Fax: +1 956665 \\ 5006; E-mail: yuanbing.mao@utrgv.edu
}

\begin{abstract}
In this work, as a fascinating 2-dimentional carbon material, reduced graphene oxide (rGO) has been decorated with $\mathrm{Ni}, \mathrm{Ni} / \mathrm{Pd}$, and $\mathrm{Ni} / \mathrm{Ag} / \mathrm{Pd}$ nanoparticles on its surface to enhance its hydrogen storage performance based on the spillover mechanism. First, graphene oxide (GO) was fabricated from graphite by a modified Hummer method. Next the GO was dispersed in water and mixed with nickel chloride, palladium chloride, and/or silver nitrate to synthesize parental $\mathrm{Ni}(\mathrm{OH})_{2} / \mathrm{GO}, \mathrm{Ni}(\mathrm{OH})_{2} / \mathrm{Pd}(\mathrm{OH})_{2} / \mathrm{GO}$, and $\mathrm{Ni}(\mathrm{OH})_{2} / \mathrm{Pd}(\mathrm{OH})_{2} / \mathrm{AgOH} / \mathrm{GO}$ hybrids through hydrothermal treatment with HMTA as a capping and precipitation agent. After in situ reduction of these parental hybrids with hydrogen flow and heat treatment at $350^{\circ} \mathrm{C}$, nanostructured $\mathrm{Ni} / \mathrm{rGO}, \mathrm{Ni} / \mathrm{Pd} / \mathrm{rGO}$, and $\mathrm{Ni} / \mathrm{Ag} / \mathrm{Pd} / \mathrm{rGO}$ hybrids were obtained. These $\mathrm{Ni}(\mathrm{Ni} / \mathrm{Pd}$, or $\mathrm{Ni} / \mathrm{Ag} / \mathrm{Pd}) / \mathrm{rGO}$ hybrids show great potential in hydrogen storage at ambient environment, as measured at room temperature (293.15K) and $800 \mathrm{mmHg}, 0.007,0.13$, and $0.055 \mathrm{wt} \%$ hydrogen adsorption capacity was obtained from the $\mathrm{Ni} / \mathrm{rGO}, \mathrm{Ni} / \mathrm{Pd} / \mathrm{rGO}$, and $\mathrm{Ni} / \mathrm{Ag} / \mathrm{Pd} / \mathrm{rGO}$ hybrids, respectively.
\end{abstract}

Keywords: Graphene; Nickel; Metallic; Spillover; Hydrogen storage 


\section{Introduction}

Hydrogen can be stored with different methods [1], including high-pressure tank, cryogenic-liquid storage, physisorption [2-5] and chemisorption [6,7]. However, conventional hydrogen storage methods have various problems such as high potential safety hazards, extreme storage conditions, low capacities, etc. Among various storage methods, adsorption in solid state materials is considered as a promising approach due to fast kinetics, excellent reversibility and high adsorption capacity possibly at low pressure and ambient temperature [8]. To store hydrogen efficiently, one of the most comment ways is to enhance adsorption capacity of solid state materials via spillover mechanism $[9,10]$. Hydrogen spillover is a phenomenon describing the transport of dissociated hydrogen generated on the first surface (like Pd), then absorbed by second surface (like carbon) $[11,12]$. This mechanism enables us to use solid materials to store hydrogen at ambient environments.

Carbon materials such as graphene [13-15], carbon nanotubes [16,17] and activated carbon [18-20] are promising candidates as hydrogen absorbents because of their high surface areas and porous structures [13-20]. For example, M. C. Tellez-Juarez et al [21] prepared activated carbon with apparent surface areas higher than $3000 \mathrm{~m}^{2} \cdot \mathrm{g}^{-1}$ and obtained hydrogen adsorption as high as $6.8 \mathrm{wt} \%$ at $-193{ }^{\circ} \mathrm{C}$ and $4 \mathrm{MPa}$. Guo et al [22] fabricated a hierarchical graphene material with a specific surface area up to $1305 \mathrm{~m}^{2} \cdot \mathrm{g}^{-1}$, which is composed of micropore $(\sim 0.8 \mathrm{~nm})$, mesopore $(\sim 4 \mathrm{~nm})$, and macropore $(>50 \mathrm{~nm})$ and shows a capacity over $4.0 \%$ at atmospheric air pressure and $77 \mathrm{~K}$. To enhance the hydrogen adsorption capacity in ambient environment, especially at room temperature, noble metals like Pd [23] and Pt [24] have been utilized to dissociate hydrogen using spillover mechanism. As an example, Zhu et al [25] synthesized Pd/PC (porous carbon) composites exhibiting an ultrahigh surface area of $2734-3316 \mathrm{~m}^{2} \cdot \mathrm{g}^{-1}$ and large pore volumes of $1.789-1.991 \mathrm{~cm}^{3} \cdot \mathrm{g}^{-1}$. The excess hydrogen uptake of the $\mathrm{Pd} / \mathrm{PC}-850$ composite reached $4.6 \mathrm{wt} \%$ at $77 \mathrm{~K}$ and 20 bar, but no measurements at room temperature were reported. Moreover, these noble metals are of great cost and limited supply. Therefore, common metals or their alloys/mixture with better performance are in demand to reduce the usage of noble metals. Alloying and core/shell mixing of metals have been 
often used to 'dilute' expensive materials by cheaper ones in order to keep desired properties while lowering cost [26].

In this work, we synthesized nanoparticles of $\mathrm{Ni}$ and its derivative (i.e. $\mathrm{Ni} / \mathrm{Pd}$ and $\mathrm{Ni} / \mathrm{Ag} / \mathrm{Pd}$ ) hybridized with reduced graphene oxide ( $\mathrm{GGO})$ to store hydrogen at both ambient temperature and pressure. Compared to similar report on pure $\mathrm{Pd}$ doped carbon materials [27,28], our $\mathrm{Ni} / \mathrm{Pd} / \mathrm{rGO}$ hybrid shows better hydrogen adsorption capacity and

excellent hydrogen reversibility. More specifically, with the use of hexamethylenetetramine (HMTA) as capping agent and in-situ reduction, we distributed $\mathrm{Ni}$ and its metallic mixture nanoparticles onto $\mathrm{rGO}$ flakes to obtain $\mathrm{Ni}(\mathrm{Ni} / \mathrm{Pd}$, $\mathrm{Ni} / \mathrm{Ag} / \mathrm{Pd} / \mathrm{rGO}$ hybrid samples. More importantly, based on hydrogen adsorption performance measured at room temperature and atmospheric pressure, the $10 \mathrm{mmol} \mathrm{Ni} / 5$ $\mathrm{mmol} \mathrm{Pd} / \mathrm{rGO}$ hybrid demonstrates the best hydrogen adsorption capacity and the $5 \mathrm{mmol}$ $\mathrm{Ni} / 5 \mathrm{mmol} \mathrm{Pd} / 5 \mathrm{mmol} \mathrm{Ag} / \mathrm{rGO}$ possesses the best adsorption-desorption reversibility among the synthesized hybrid samples.

\section{Experimental}

\subsection{Chemicals}

Nickel(II) chloride hexahydrate $(\geq 98 \%)$, palladium(II) chloride $(\geq 99.9 \%)$, hexamethylenetetramine (HMTA, 99\%), nitric acid (ACS reagent, 70\%) and hydrogen peroxide (30-32\%) were purchased from Sigma-Aldrich. Graphite powder (APS 7-11 micron, 99\%) and potassium permanganate (98\%) were obtained from Alfa Aesar, silver nitrate (ACS reagent) was from VWR scientific, sulfuric acid was from Acros, and hydrochloric acid was from Fisher scientific. All chemicals were used as received without further purification.

\subsection{Synthesis of $\mathrm{Ni} / \mathrm{rGO}, \mathrm{Ni} / \mathrm{Pd} / \mathrm{rGO}$ and $\mathrm{Ni} / \mathrm{Pd} / \mathrm{Ag} / \mathrm{rGO}$ hybrids}

Graphene oxide (GO) was prepared from graphite flakes according to a modified Hummers' method [29]. $1 \mathrm{~g}$ of GO was dispersed in $200 \mathrm{~mL}$ water by sonication for 30 min to form $\mathrm{GO}$ water dispersion, $15 \mathrm{mmol}$ of $\mathrm{NiCl}_{2} \cdot 6 \mathrm{H}_{2} \mathrm{O}$ and $30 \mathrm{mmol}$ of HMTA were added into the dispersion, and then stirred for $20 \mathrm{~min}$. The homogeneous mixture was separated and transferred to two $100 \mathrm{~mL}$ autoclave and hydrothermally reacted at $120{ }^{\circ} \mathrm{C}$ for 1 hour to obtain parental $\mathrm{Ni}(\mathrm{OH})_{2} / \mathrm{GO}$ hybrid. To make parental 
$\mathrm{Ni}(\mathrm{OH})_{2} / \mathrm{Pd}(\mathrm{OH})_{2} / \mathrm{GO}$ hybrid, $\mathrm{PdCl}_{2}$ and $\mathrm{HMTA}$ were added to the obtained parental $\mathrm{Ni}(\mathrm{OH})_{2} / \mathrm{GO}$ hybrid followed with another hydrothermal reaction at $120{ }^{\circ} \mathrm{C}$ for 1 hours. To make parental $\mathrm{Ni}(\mathrm{OH})_{2} / \mathrm{AgOH} / \mathrm{Pd}(\mathrm{OH})_{2} / \mathrm{GO}$ hybrid, $\mathrm{AgNO}_{3}$ and $\mathrm{HMTA}$ were first added to the obtained parental $\mathrm{Ni}(\mathrm{OH})_{2} / \mathrm{GO}$ hybrid followed with a hydrothermal reaction at $120{ }^{\circ} \mathrm{C}$ for another 1 hour. After that, $\mathrm{PdCl}_{2}$ and $\mathrm{HMTA}$ were added to the $\mathrm{Ni}(\mathrm{OH})_{2} / \mathrm{AgOH} / \mathrm{GO}$ hybrid and followed with another hydrothermal reaction at $120{ }^{\circ} \mathrm{C}$ for 2 hours. Black solid products from the hydrothermal synthesis were separated by filtration, washed with DI water and dried at $70{ }^{\circ} \mathrm{C}$ under vacuum. After that, the black solids of these parental hybrids were reduced at $350{ }^{\circ} \mathrm{C}$ for 2 hours under continuous hydrogen flow to obtain $\mathrm{Ni}(\mathrm{Ni} / \mathrm{Pd}, \mathrm{Ni} / \mathrm{Ag} / \mathrm{Pd}) / \mathrm{rGO}$ hybrids. To be comparative, the total moles of metal salts initially introduced into $1 \mathrm{~g}$ of $\mathrm{GO}$ were kept at $15 \mathrm{mmol}$, i.e. 15 mmol of $\mathrm{NiCl}_{2} \cdot 6 \mathrm{H}_{2} \mathrm{O}$ was used to generate the $\mathrm{Ni} / \mathrm{rGO}$ hybrid, $10 \mathrm{mmol}$ of $\mathrm{NiCl}_{2} \cdot 6 \mathrm{H}_{2} \mathrm{O}$ and $5 \mathrm{mmol}$ of $\mathrm{PdCl}_{2}$ were used to generate the $\mathrm{Ni} / \mathrm{Pd} / \mathrm{rGO}$ hybrid, and $5 \mathrm{mmol}$ of $\mathrm{NiCl}_{2} \cdot 6 \mathrm{H}_{2} \mathrm{O}, 5 \mathrm{mmol}$ of $\mathrm{AgNO}_{3}$ and $5 \mathrm{mmol}$ of $\mathrm{PdCl}_{2}$ were used to produce the $\mathrm{Ni} / \mathrm{Ag} / \mathrm{Pd} / \mathrm{rGO}$ hybrid. As a contrast, corresponding rGO sample without hybridizing with metallic nanoparticles was synthesized for comparison by processing the prepared GO through the whole synthesis procedure. The synthesis process for the $\mathrm{Ni} / \mathrm{rGO}, \mathrm{Ni} / \mathrm{Pd} / \mathrm{rGO}$ and $\mathrm{Ni} / \mathrm{Ag} / \mathrm{Pd} / \mathrm{rGO}$ hybrids was schematically demonstrated as Figure 1 below.

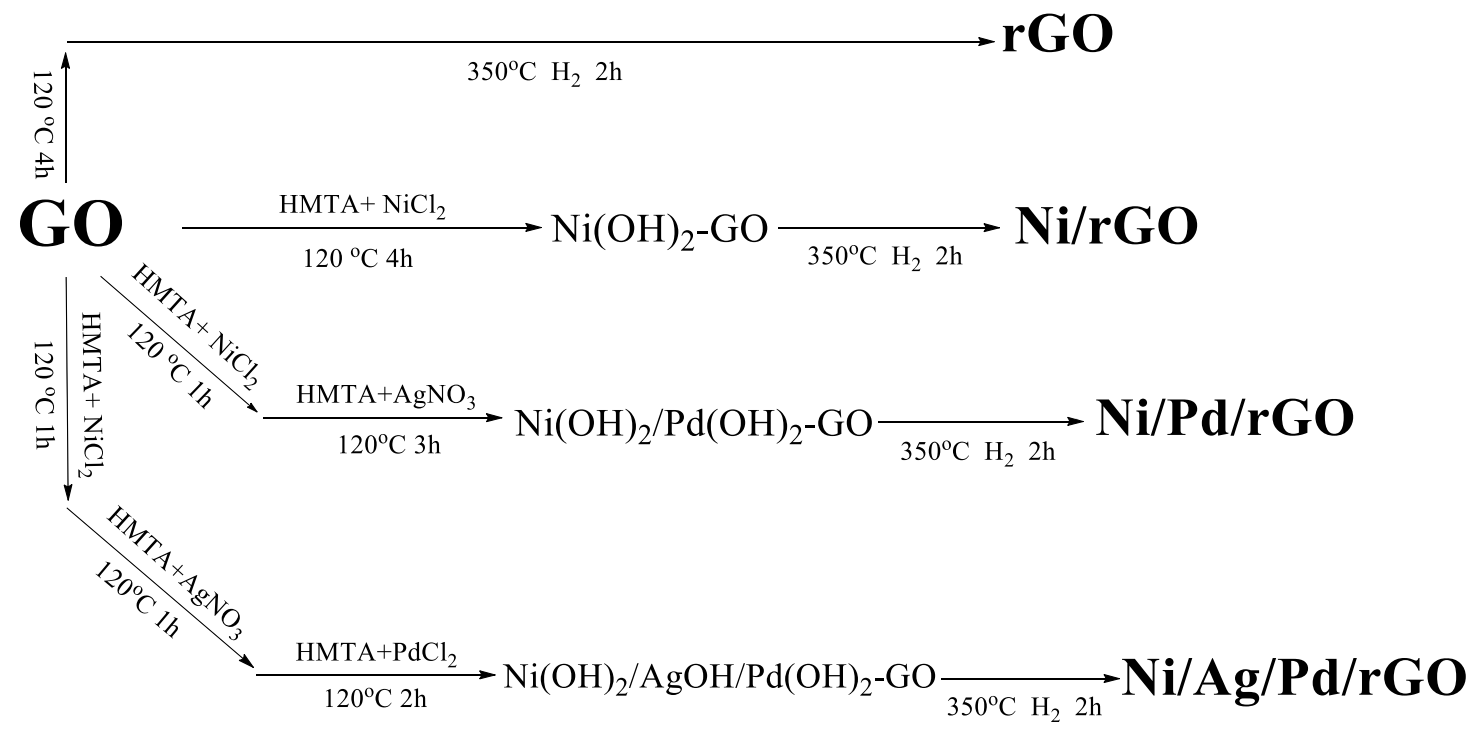

Figure 1. Schematic diagram of the synthesis procedure of the $\mathrm{Ni}(\mathrm{Ni} / \mathrm{Pd}, \mathrm{Ni} / \mathrm{Ag} / \mathrm{Pd}) / \mathrm{rGO}$ hybrid samples. 


\subsection{Characterization}

The morphology of the $\mathrm{Ni}(\mathrm{Ni} / \mathrm{Pd}, \mathrm{Ni} / \mathrm{Ag} / \mathrm{Pd})$ and $\mathrm{rGO}$ hybrid samples was investigated by a field-emission scanning electron microscopy (FESEM, Sigma VP Carl Zeiss, Germany). Energy-dispersive spectroscopy (EDS) was used to analysis element composite of these hybrids tested with EDAX detector equipped on the FESEM. The average diameter of the metallic nanoparticles was measured using the image analysis software Gatan Digital Micrograph (V2.3). Powder X-ray diffraction (XRD) was performed with a Rigaku Miniflex diffractometer. Raman spectra were taken by a SENTERRA Dispersive Raman Microscope which equipped with a $785 \mathrm{~nm}$ laser source. $\mathrm{X}$-ray photoelectron spectroscopy (XPS) was performed on a Thermo Scientific Ka spectrometer with monochromatic $\mathrm{Al}_{\mathrm{k} \alpha}$ radiation $(1486.6 \mathrm{eV})$. The peak areas were quantified by its accompanying casaXPS (V2.3.16) software. Porosimetry analysis (BET surface area, BJH pore volume/pore area) and hydrogen sorption measurements were performed on a Micromeritics ASAP 2020 Surface Area and Porosity Analyzer. A reference material (silica-alumina) provided by Micromeritics Company was tested to assure the accuracy of equipment. Nitrogen adsorption analyses were performed at $77 \mathrm{~K}$ after a preparatory degassing at $300{ }^{\circ} \mathrm{C}, 2 \mu \mathrm{m} \mathrm{Hg}$ pressure for $>12$ hours. Hydrogen adsorption analyses were performed at room temperature $(295.15 \mathrm{~K})$ after the same degassing procedure.

\section{Results and discussion}

\subsection{SEM imaging}

Figures $2 \mathrm{a} \& 2 \mathrm{~b}$ show the morphology of the GO and rGO samples, which were obtained with the modified Hummer method and with the same treatment at $350{ }^{\circ} \mathrm{C}$ under continuous hydrogen flow as the hybrid samples of rGO and $\mathrm{Ni}$ or its metallic mixtures, respectively. Figures 2c-h show the morphology and the EDS spectra of the corresponding $\mathrm{Ni} / \mathrm{rGO}, \mathrm{Ni} / \mathrm{Pd} / \mathrm{rGO}$ and $\mathrm{Ni} / \mathrm{Ag} / \mathrm{Pd} / \mathrm{rGO}$ hybrid samples. The concentration of metal as per EDS spectra provided in supplemental inf.1. The SEM images illustrated that metallic $\mathrm{Ni}, \mathrm{Ni} / \mathrm{Pd}, \mathrm{Ni} / \mathrm{Ag} / \mathrm{Pd}$ nanoparticles with diameter varying from 10 to $110 \mathrm{~nm}$ were well distributed on the rGO sheets. The diameters of the Ni, Ni/Pd, and Ni/Ag/Pd particles vary because of the difference of metal precursor introducing sequence and their 
reduction activities. More specifically, Fig. 2c illustrated that the Ni nanoparticles were of $\sim 13 \mathrm{~nm}$. When the Ni precursor was firstly introduced, its low reduction activity resulted in the smallest particles in this series of samples. In Fig. 2e, it can be see that the $\mathrm{Ni} / \mathrm{Pd}$ nanoparticles grew to $\sim 30 \mathrm{~nm}$. The $\mathrm{Pd}$ precursor $\mathrm{PdCl}_{2}$ was added into the $\mathrm{Ni}(\mathrm{OH})_{2} / \mathrm{GO}$ system and it is believed that metallic Pd layer was wrapped on the Ni NP surface as further confirmed by the EDS spectrum in Fig. 2f. Therefore the average diameter of the Ni/Pd nanoparticles increased. Fig. $2 \mathrm{~g}$ clearly shows the diameter of the $\mathrm{Ni} / \mathrm{Ag} / \mathrm{Pd}$ particles varies from $40-110 \mathrm{~nm}$. It is because the reduction activities of $\mathrm{Pd}$ and $\mathrm{Ag}$ precursors are much higher than that of the Ni precursor, thus some particles contain mainly Pd and/or Ag and have bigger size. The increasing trend of the diameter of these metallic nanoparticles following that of their reduction activity indirectly proved that they are composed of corresponding metal layers. 

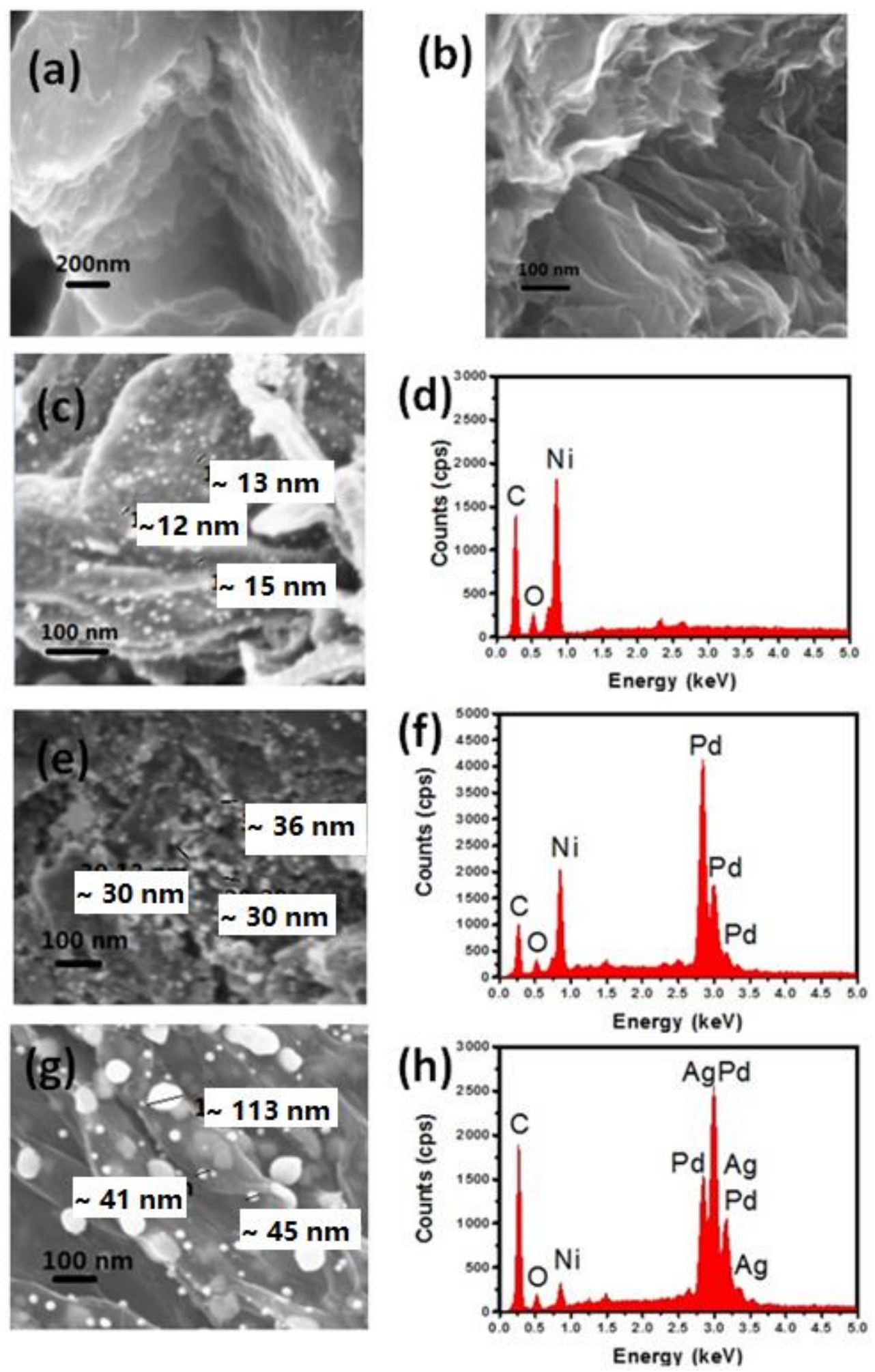

Figure 2. (a) SEM image of the GO; (b) SEM image of the rGO; SEM images and EDS spectra of the hybrids: (c \& d) the Ni/rGO hybrid; (e \& f) the Ni/Pd/rGO hybrid; and (g \& h) the Ni/Ag/Pd/rGO hybrid. 
Moreover, it can be clearly seen from these SEM images that the metal nanoparticles inserted into the rGO layers (Figures $2 \mathrm{a} \& \mathrm{~b} v s 2 \mathrm{c}, 2 \mathrm{e} \& 2 \mathrm{~g}$ ). It is believed that during the hydrothermal reaction, graphene oxide dispersed in water and reacted with the metal precursors. These metal precursors then hydrolyzed into metal hydroxide nanoparticles as assisted and controlled by the added HMTA, and these metal hydroxide nanoparticles decorated onto the GO surface. After the hydrothermal reaction, the GO sheets tended to stack back as shown in Fig. 2a but were prevented with the metal hydroxide nanoparticles decorated on their surface. Therefore, as observed here, the metallic Ni, Ni/Pd, Ni/Ag/Pd nanoparticles presented between the rGO layers after the hydrogen reduction process at $350{ }^{\circ} \mathrm{C}$.

\subsection{XRD patterns}

Fig. 3A shows the X-ray diffraction patterns of the synthesized $\mathrm{Ni}(\mathrm{Ni} / \mathrm{Pd}$, $\mathrm{Ni} / \mathrm{Ag} / \mathrm{Pd}$ )/rGO hybrids accompanied with that of the synthesized rGO. As seen, the $\mathrm{rGO}$ sample showed a very broad peak around $2 \theta=26^{\circ}$, all of the hybrid samples have this peak at the same position (shown in Fig. 3B), due to reduced graphene oxide is highly disorder, they can't show distinguish peaks, enlarged XRD peaks shows in Fig. 3B. And in Fig. $3 \mathrm{C}$, there is a peak in $11^{\circ}$ shows in GO sample, but no peaks at the same position for $\mathrm{rGO}$ or metal/rGO samples, which confirms the existence of $\mathrm{rGO}$ in these hybrid samples. XRD patterns of $\mathrm{Ni} / \mathrm{rGO}$ demonstrated that there were two types of Ni crystal structures, i.e. cubic and hexagonal phases. By comparing the XRD patterns of the $\mathrm{Ni} / \mathrm{rGO}, \mathrm{Ni} / \mathrm{Pd} / \mathrm{rGO}$ and $\mathrm{Ni} / \mathrm{Ag} / \mathrm{Pd} / \mathrm{rGO}$ hybrid samples, the intensity of corresponding $\mathrm{Ni}$ peaks decreased in this sequence, which confirms that the Ni percentage decreased in these samples as the initial amount (and so as the ratio) of the introduced $\mathrm{Ni}$ salt decreased in the sequence of $\mathrm{Ni} / \mathrm{rGO}, \mathrm{Ni} / \mathrm{Pd} / \mathrm{rGO}$ and $\mathrm{Ni} / \mathrm{Ag} / \mathrm{Pd} / \mathrm{rGO}$. This is also in agreement with the metal concentration change in EDS analysis (see Figure S1). Obvious intensity difference between the diffraction peaks from metallic $\mathrm{Ni}$ and $\mathrm{Pd}$ is consistent with the fact that the reduction activity of the used $\mathrm{Ni}$ precursor $\mathrm{NiCl}_{2}$ was weaker than that of the Pd precursor $\mathrm{PdCl}_{2}$, which resulted in the observed phenomenon that the $\mathrm{Ni}$ nanoparticles is much smaller that its metallic mixture counterpart $\mathrm{Ni} / \mathrm{Pd}$ and the relative percentage of $\mathrm{Ni}$ is low. In the XRD pattern of the $\mathrm{Ni} / \mathrm{Ag} / \mathrm{Pd} / \mathrm{rGO}$ hybrid, the diffraction 
peak intensities from $\mathrm{Ag}$ and $\mathrm{Pd}$ are at the same height due to the facts that these two metal precursors $\mathrm{PdCl}_{2}$ and $\mathrm{AgNO}_{3}$ have similar reduction activities and were added with the same molar amount. Blue shift of the Pd peak position was observed when comparing the XRD patterns from the $\mathrm{Ni} / \mathrm{Pd} / \mathrm{rGO}$ and $\mathrm{Ni} / \mathrm{Ag} / \mathrm{Pd} / \mathrm{rGO}$ hybrids. The possible explanation for this phenomenon is because of slight substitution of $\mathrm{Ag}$ into Pd lattice due to their similar atom radii, which resulted in twists of the Pd crystal structure, as previously observed in Pd-Ag alloy sample [30].
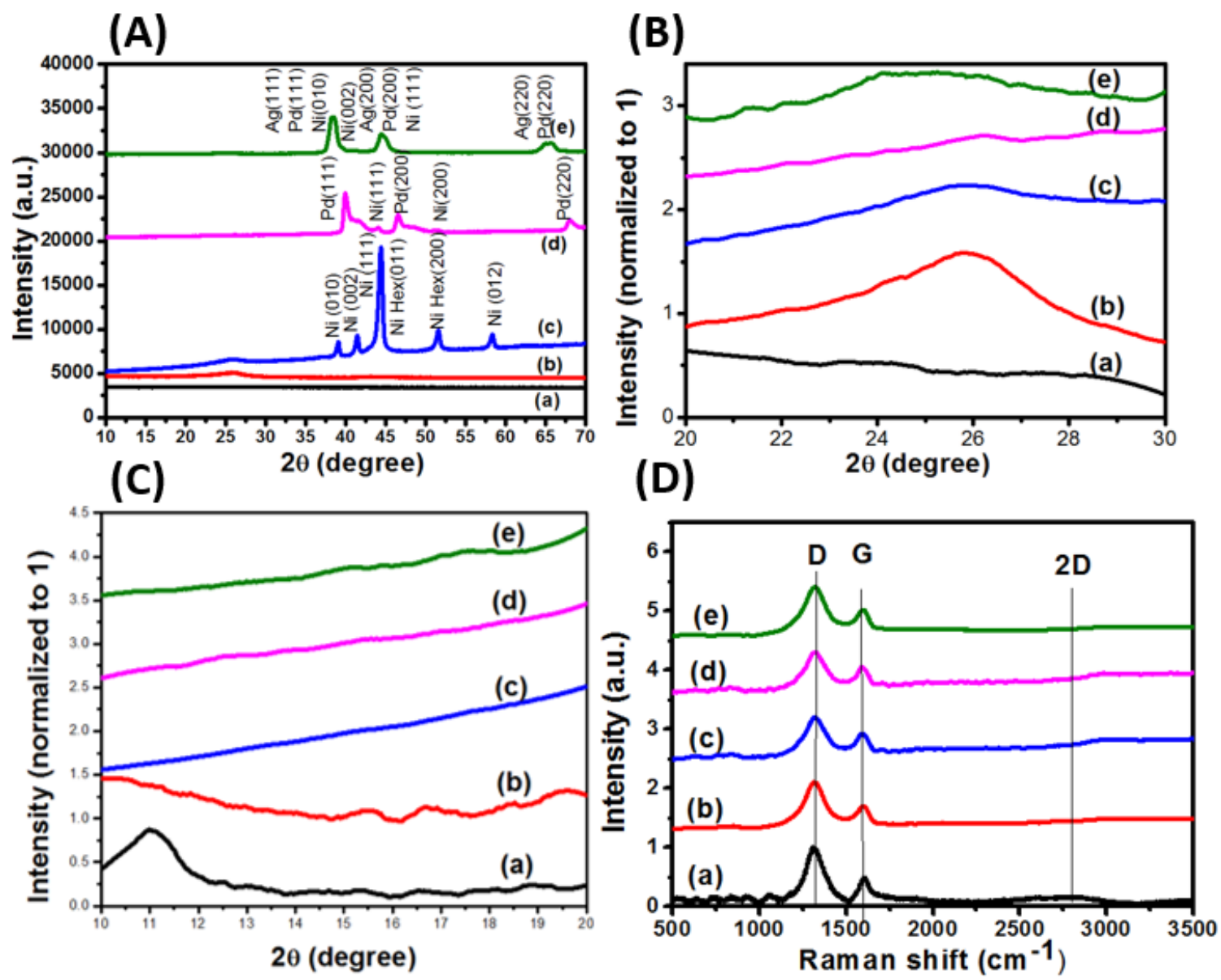

Figure 3. (A) XRD patterns; (B) enlarged XRD patterns shown in (A) in the range of 20o 30o; (C) zoomed in XRD patterns shown in (A) in the range of 10o 20o; and (D) normalized Raman spectra of (a) GO, (b) rGO, (c) Ni/rGO, (d) Ni/Pd/rGO, and (e) $\mathrm{Ni} / \mathrm{Ag} / \mathrm{Pd} / \mathrm{rGO}$ samples. 


\subsection{Raman analysis}

Fig. 3D presents the Raman spectra of the GO, rGO, and $\mathrm{Ni}(\mathrm{Ni} / \mathrm{Pd}, \mathrm{Ni} / \mathrm{Ag} / \mathrm{Pd})$ and $\mathrm{rGO}$ hybrid samples with two distinct peaks of carbon at around $1355 \mathrm{~cm}^{-1}$ (D peak) and 1594 $\mathrm{cm}^{-1}$ (G peak). The intensity ratio of these two bands, $I(\mathrm{D}) / I(\mathrm{G})$, can be used to characterize surface defect density of graphene sheets [31-33]. In high-defect-density regime, the intensity ratio $I(\mathrm{D}) / I(\mathrm{G})=D(\lambda) \cdot L_{\mathrm{D}}{ }^{2},[34]$ where $D(\lambda)$ is the constant depend on laser excitation wavelength and $L_{\mathrm{D}}$ is distance between defects. According to the Raman spectra, the $\mathrm{Ni} / \mathrm{Ag} / \mathrm{Pd} / \mathrm{rGO}$ hybrid had the highest $I(\mathrm{D}) / I(\mathrm{G}) \approx 1.64$, which revealed that its defect distance was the smallest, in other words, this $\mathrm{Ni} / \mathrm{Ag} / \mathrm{Pd} / \mathrm{rGO}$ hybrid has more defects compared to the other samples. Compared to the $\mathrm{Ni} / \mathrm{rGO}$ and $\mathrm{Ni} / \mathrm{Pd} / \mathrm{rGO}$ hybrids with $I(\mathrm{D}) / I(\mathrm{G}) \approx 1.37$ and 1.43 respectively, the $\mathrm{Ni} / \mathrm{Ag} / \mathrm{Pd} / \mathrm{rGO}$ hybrid underwent the longest reaction time. Repeated heating-up and cooling-down during the synthesis made the $\mathrm{Ni} / \mathrm{Ag} / \mathrm{Pd} / \mathrm{rGO}$ hybrid tended to generate the most atomic-scale defects while the $\mathrm{Ni} / \mathrm{rGO}$ hybrid had the least defects on graphene layers.

Moreover, there were smooth board peak rises around $2700 \mathrm{~cm}^{-1}$, where the 2D peak of graphene is located. It is reported that the Raman peaks of $2 \mathrm{D}$ graphene stacks would become boarder and shift to higher wavenumber because of increasing layers of graphene [33]. In Fig. 3B, the 2D graphene peak from the Ni, Ni/Pd, Ni/Ag/Pd/rGO hybrid samples shifted to higher wavenumber and became broader, which means graphene layers stacked back together and is in agreement with nitrogen adsorption isotherms shown in Fig. 5 below.

\subsection{XPS analysis}

Fig. 4 demonstrated the XPS $\mathrm{C} 1 \mathrm{~s}$ spectra of $\mathrm{GO}, \mathrm{rGO}, \mathrm{Ni} / \mathrm{rGO}, \mathrm{Ni} / \mathrm{Pd} / \mathrm{rGO}$ and $\mathrm{Ni} / \mathrm{Ag} / \mathrm{Pd} / \mathrm{rGO}$ hybrid samples, which confirms the reduction of the parental metal hydroxide and GO hybrids into the corresponding $\mathrm{Ni}$ and its metallic mixture with $\mathrm{rGO}$ hybrids from these XPS measurements. As shown in Fig. 4a, the C1s spectra of GO can be convoluted into three peaks at 284.5, 286.3 and $287.6 \mathrm{eV}$ via gauss fitting, which corresponded to $\mathrm{C}-\mathrm{C} / \mathrm{C}=\mathrm{C}, \mathrm{C}-\mathrm{OH}$ and $\mathrm{C}=\mathrm{O}$ functional groups [35], respectively. It is also consistent with what have been reported in the literature that the major functional group of GO are hydroxyl, carboxyl and epoxy groups [36]. Comparing Fig. 4a to Fig. 4c-e, the 
$\mathrm{C}-\mathrm{OH}$ intensity in the metal/rGO hybrid samples decreased tremendously. Large quantity removal of $\mathrm{C}-\mathrm{OH}$ and $\mathrm{C}=\mathrm{O}$ groups and the increasing amount of $\mathrm{C}-\mathrm{C} / \mathrm{C}=\mathrm{C}$ groups indicated the successful reduction of GO into rGO. This observation in agree with the previous study on similar Ni/rGO hybrids [37].

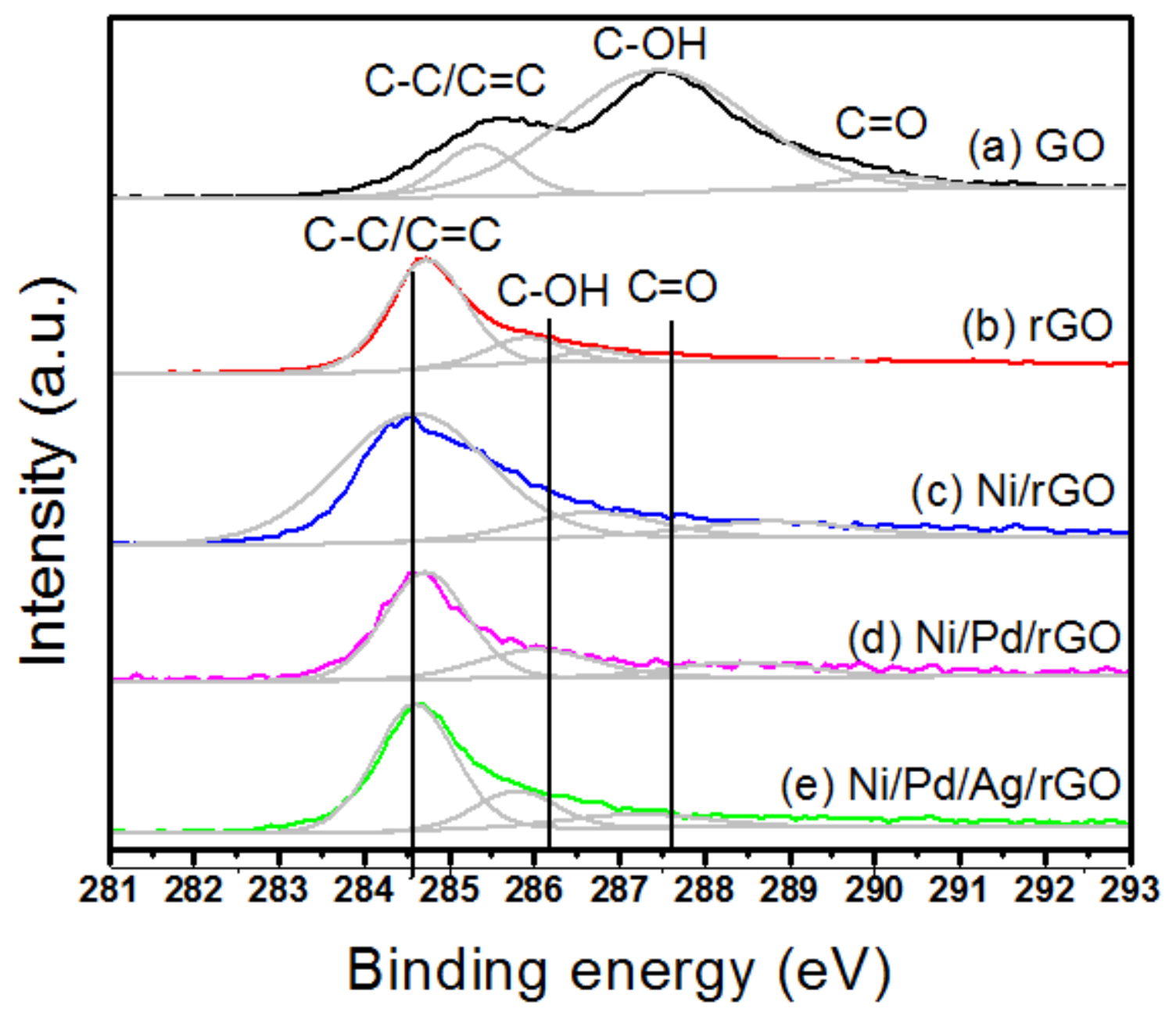

Figure 4. XPS C1s spectra of (a) GO; (b) $\mathrm{rGO}$; (c) $\mathrm{Ni} / \mathrm{rGO}$; (d) $\mathrm{Ni} / \mathrm{Pd} / \mathrm{rGO}$; and (e) $\mathrm{Ni} / \mathrm{Ag} / \mathrm{Pd} / \mathrm{rGO}$ hybrids.

3.5 Porosimetry (BET surface area and BJH pore volume)

Fig. 5 shows the nitrogen adsorption isotherms taken at $77 \mathrm{~K}$ for GO, rGO, and Ni series rGO hybrids. The isotherms of $\mathrm{Ni}(\mathrm{Ni} / \mathrm{Pd}, \mathrm{Ni} / \mathrm{Ag} / \mathrm{Pd})$ with $\mathrm{rGO}$ hybrid samples exhibited 
the typical type III adsorption, indicating the formation of adsorbate multilayers and the weak adsorbate-adsorbent interactions [38]. We found that $\mathrm{Ni} / \mathrm{rGO}$ had a delay in $\mathrm{N}_{2}$ desorption as the first $\mathrm{N}_{2}$ adsorption-desorption hysteresis observed, however this hysteresis did not happen from other two hybrid samples. The Ni/rGO hybrid with the highest percentage of $\mathrm{Ni}$ is the only one who had delay in desorption. The difference of these hybrids was probably due to composition of metallic nanoparticles. It can be inferred that $\mathrm{Pd}$ and $\mathrm{Ag}$ may be helpful to reduce the hysteresis in gas adsorption and $\mathrm{Ni}$ alone might not be as good as these two metals. Thus it may be beneficial to control the $\mathrm{Ni}$ percentage in certain range for the reversible gas desorption of this type of hybrids while further study is necessary on this aspect.

Corresponding BET surface area and BJH pore volume values were calculated from the scale of relative pressure from 0.06 to $0.2 \mathrm{P} / \mathrm{P}_{0}$ and shown in Table 1. After series of treatment, GO turns to curly rGO hence the surface area increase from $\sim 33$ to $\sim 119 \mathrm{~m}^{2} / \mathrm{g}$. And it can be observed that the $\mathrm{Ni} / \mathrm{rGO}, \mathrm{Ni} / \mathrm{Pd} / \mathrm{rGO}, \mathrm{Ni} / \mathrm{Ag} / \mathrm{Pd} / \mathrm{rGO}$ hybrids exhibited decreasing trend in BET surface area and pore volume as more types of metals were introduced into the hybrid system. This trend is because curly graphene surface were occupied by metal nanoparticles. As shown by the SEM images in Fig. 2, metal nanoparticles became bigger when more types of metals were added. Therefore the surface area and pore volume of the $\mathrm{Ni}(\mathrm{Ni} / \mathrm{Pd}, \mathrm{Ni} / \mathrm{Ag} / \mathrm{Pd}) / \mathrm{rGO}$ hybrid samples had reduced. According to Raman analysis in Fig. 3B, the graphene sheets in the hybrid samples stacked back, but they could not fully stack back to intense graphite structure due to the insertion of the metallic nanoparticles between the rGO layers. Hence $\mathrm{Ni}(\mathrm{Ni} / \mathrm{Pd}$, $\mathrm{Ni} / \mathrm{Ag} / \mathrm{Pd} / \mathrm{rGO}$ hybrids have BET surface area of $\sim 30 \mathrm{~m}^{2} / \mathrm{g}$, which is similar to GO sample. 


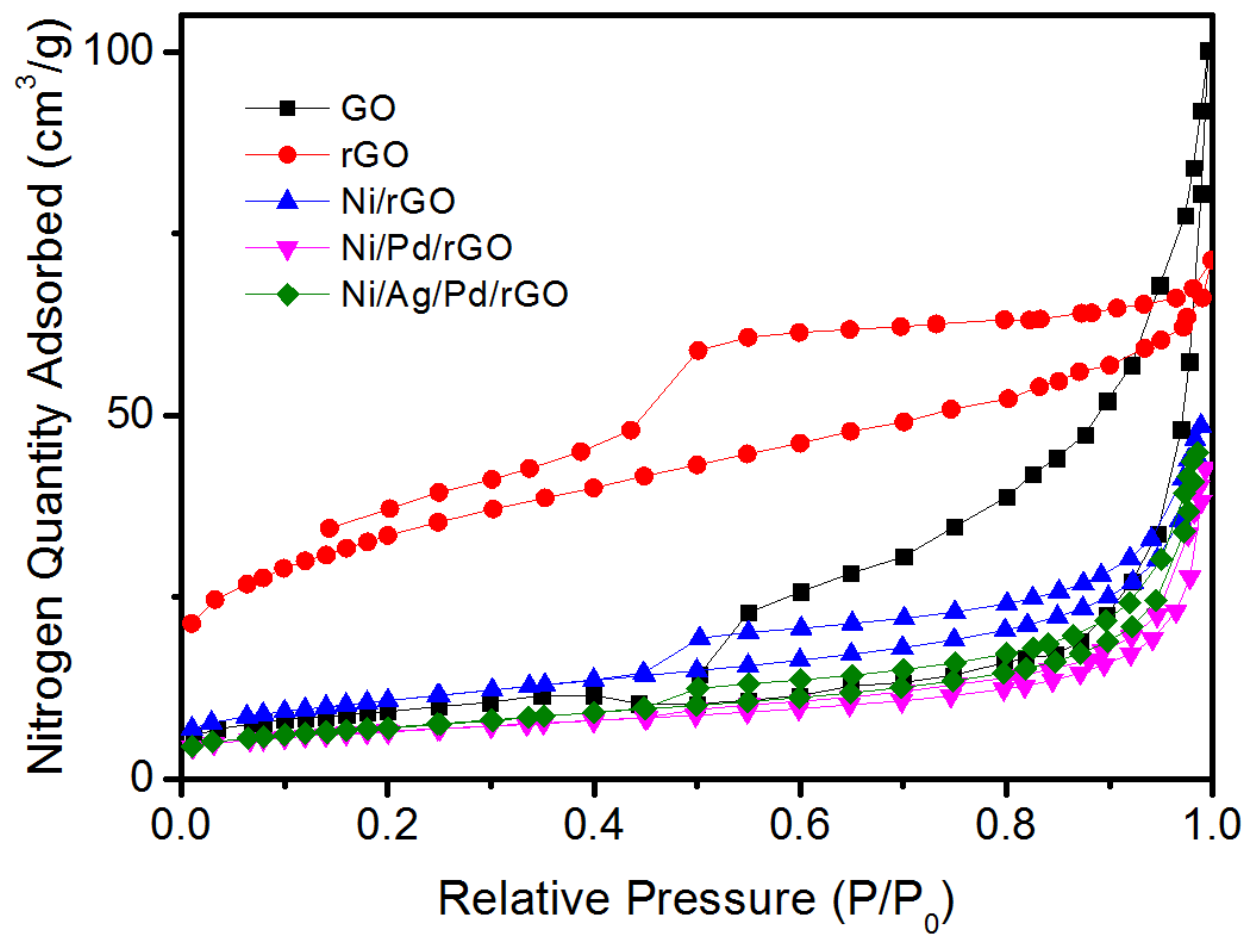

Figure 5. Nitrogen adsorption isotherms of the $\mathrm{GO}, \mathrm{rGO}, \mathrm{Ni} / \mathrm{rGO}, \mathrm{Ni} / \mathrm{Pd} / \mathrm{rGO}$ and $\mathrm{Ni} / \mathrm{Ag} / \mathrm{Pd} / \mathrm{rGO}$ hybrid samples at $77 \mathrm{~K}$.

Table 1 Porosity analysis of the GO, rGO, Ni/rGO, Ni/Pd/rGO and Ni/Ag/Pd/rGO hybrid samples from the nitrogen adsorption isotherm analysis at $77 \mathrm{~K}$.

\begin{tabular}{cccccc}
\hline & GO & rGO & Ni/rGO & Ni/Pd/rGO & Ni/Ag/Pd/rGO \\
\hline $\begin{array}{c}\text { BET Surface } \\
\text { Area }\left(\mathrm{m}^{2} / \mathrm{g}\right)\end{array}$ & 33.0275 & 119.7858 & 38.6597 & 25.4270 & 23.3813 \\
$\begin{array}{c}\text { BJH pore } \\
\text { volume }\left(\mathrm{cm}^{3} / \mathrm{g}\right)\end{array}$ & 0.0743 & 0.0962 & 0.0734 & 0.0713 & 0.0645 \\
\hline
\end{tabular}

\subsection{Hydrogen storage application}

Fig. 6 shows the hydrogen adsorption performance of the GO, rGO, and $\mathrm{Ni} / \mathrm{rGO}$, $\mathrm{Ni} / \mathrm{Pd} / \mathrm{rGO}, \mathrm{Ni} / \mathrm{Ag} / \mathrm{Pd} / \mathrm{rGO}$ hybrids at $295 \mathrm{~K}$. At $295 \mathrm{~K}$ and $800 \mathrm{mmHg}$, the hydrogen uptake capacity of the $\mathrm{Ni} / \mathrm{rGO}, \mathrm{Ni} / \mathrm{Pd} / \mathrm{rGO}$ and $\mathrm{Ni} / \mathrm{Ag} / \mathrm{Pd} / \mathrm{rGO}$ was measured to be $0.007 \%, 0.13 \%$ and $0.055 \%$, respectively, while GO and rGO have negligible hydrogen uptake capacity as expected under the ambient conditions. In comparison with the GO and $\mathrm{rGO}$ contrast samples, the $\mathrm{Ni} / \mathrm{Pd} / \mathrm{rGO}$ and $\mathrm{Ni} / \mathrm{Ag} / \mathrm{Pd} / \mathrm{rGO}$ hybrid sample demonstrated greatly enhanced hydrogen adsorption uptake capacity. Moreover, our 
$\mathrm{Ni} / \mathrm{Pd} / \mathrm{rGO}$ and $\mathrm{Ni} / \mathrm{Ag} / \mathrm{Pd} / \mathrm{rGO}$ hybrid samples possess higher hydrogen adsorption capacities than the $\mathrm{Pd} /$ carbon (activated carbon, graphene/activated carbon) hybrids at room temperature $(298 \mathrm{~K})$ and atmospheric pressure $(0.1 \mathrm{MPa})$ reported on the literature with corresponding values of $0.08 \mathrm{wt} \%$ [27] and $0.018 \%$ [28], respectively. Thus, the Ni mixtures of $\mathrm{Ni} / \mathrm{Pd}$ and $\mathrm{Ni} / \mathrm{Ag} / \mathrm{Pd}$ are good candidates to replace bulk $\mathrm{Pd}$ as surface decoration catalysts on large surface carbon materials for hydrogen adsorption, especially based on the spillover mechanism at ambient conditions.

Hydrogen adsorption isotherms in Fig. 6 also reveal that the Ni/rGO hybrid does not have very active hydrogen adsorption performance due to the low spillover activity of $\mathrm{Ni}$, and the high hydrogen storage performance of our $\mathrm{Ni} / \mathrm{Pd} / \mathrm{rGO}$ and $\mathrm{Ni} / \mathrm{Ag} / \mathrm{Pd} / \mathrm{rGO}$ hybrid samples at ambient environment can be attributed to the excellent spillover activity of the $\mathrm{Pd}$ component [39]. The $\mathrm{Ni} / \mathrm{Pd}$ nanoparticles on the rGO surface make $\mathrm{Pd}$ atoms from the $\mathrm{Ni} / \mathrm{Pd} / \mathrm{rGO}$ hybrid sample has high surface area to maintain good contact with $\mathrm{H}_{2}$ molecules, even with low amount of $\mathrm{Pd}$ and eventually in the $\mathrm{Ni} / \mathrm{Pd} / \mathrm{rGO}$ hybrid. Therefore, it is believed that our $\mathrm{Ni}(\mathrm{Ni} / \mathrm{Pd}, \mathrm{Ni} / \mathrm{Ag} / \mathrm{Pd}) / \mathrm{rGO}$ hybrid approach and sample preparation procedure reported here are promising to enhance their adsorption capacity for hydrogen molecules by decorating high surface porous materials with metal nanoparticles. At the meantime, we also realized that not all the metallic particle mixtures are favorable for hydrogen storage based on the spillover mechanism. Particularly, the $\mathrm{Ni} / \mathrm{Ag} / \mathrm{Pd} / \mathrm{rGO}$ hybrid did not show performance as good as the $\mathrm{Ni} / \mathrm{Pd} / \mathrm{rGO}$ sample. Therefore, the composition of metal particles [40] is also a very important factor affecting hydrogen spillover activities.

Moreover, the reversibility of adsorption and desorption performance of an adsorbent is another key factor for its commercial use as a hydrogen storage material [41]. For their full usage, hydrogen adsorbent materials need to be able to fully desorb hydrogen as well in ambient environment after adsorption. In our cases, the $\mathrm{Ni}(\mathrm{Ni} / \mathrm{Pd}, \mathrm{Ni} / \mathrm{Ag} / \mathrm{Pd}) / \mathrm{rGO}$ hybrid samples exhibited very good reversibility at room temperature and atmospheric pressure. Among these samples, the $\mathrm{Ni} / \mathrm{Ag} / \mathrm{Pd} / \mathrm{rGO}$ hybrid had the best hydrogen adsorption-desorption reversibility performance even though its hydrogen uptake capability is only half of the $\mathrm{Ni} / \mathrm{Pd} / \mathrm{rGO}$ hybrid. This is because the size of the $\mathrm{Ni} / \mathrm{Ag} / \mathrm{Pd}$ metallic nanoparticles in the $\mathrm{Ni} / \mathrm{Ag} / \mathrm{Pd} / \mathrm{rGO}$ hybrid sample is the biggest compared to 
those in the other two hybrids. The contact and space between rGO surface and the $\mathrm{Ni} / \mathrm{Ag} / \mathrm{Pd}$ metallic nanoparticles provide a 'highway' for $\mathrm{H}_{2}$ gas molecules to quickly adsorb and desorb, therefore the $\mathrm{Ni} / \mathrm{Ag} / \mathrm{Pd} / \mathrm{rGO}$ hybrid sample shows the best reversibility.

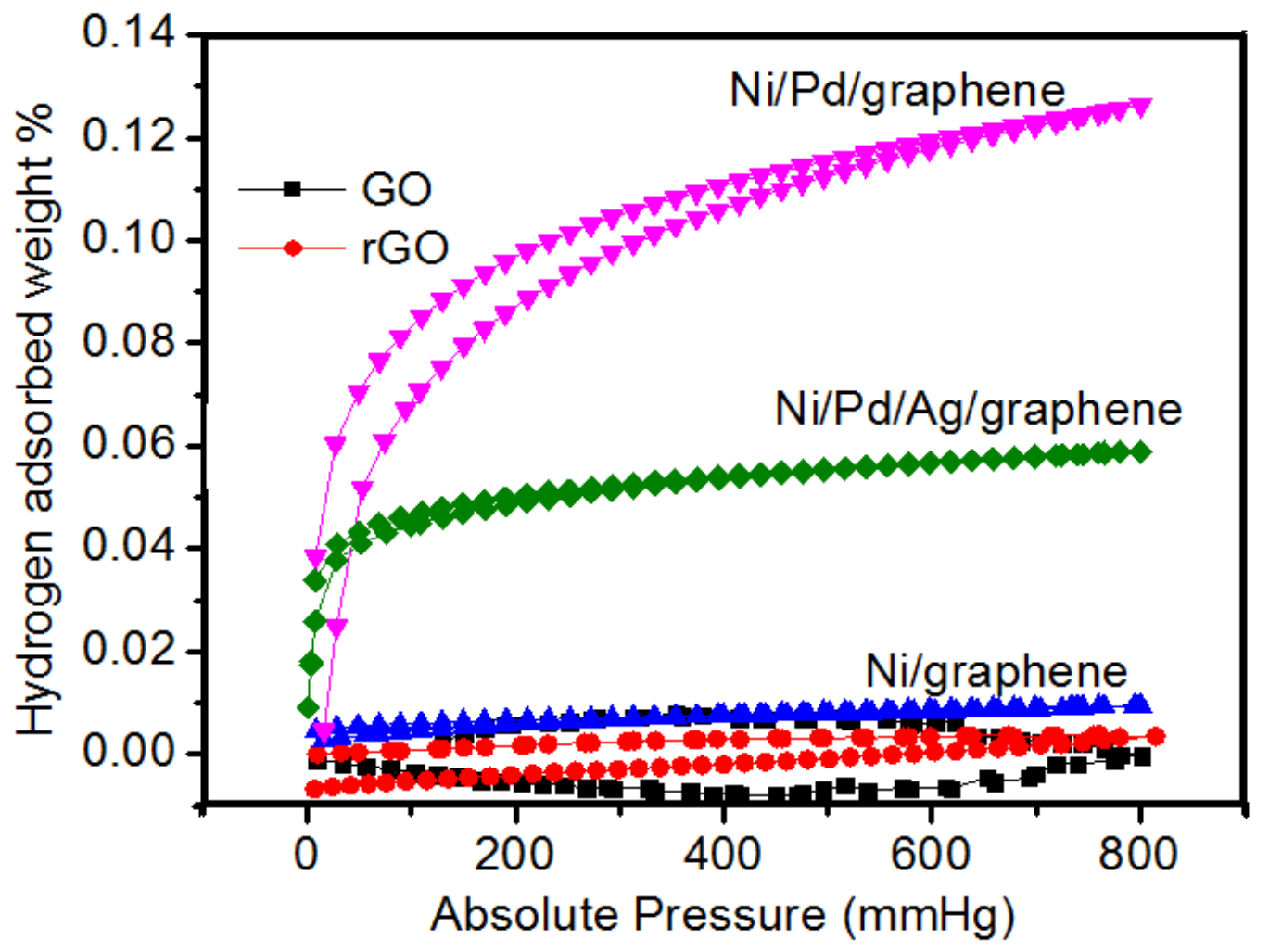

Figure 6. Hydrogen adsorption performance of the $\mathrm{GO}, \mathrm{rGO}, \mathrm{Ni} / \mathrm{rGO}, \mathrm{Ni} / \mathrm{Pd} / \mathrm{rGO}$ and $\mathrm{Ni} / \mathrm{Ag} / \mathrm{Pd} / \mathrm{rGO}$ hybrid samples measured at $295 \mathrm{~K}$.

\section{Conclusions}

In this study, $\mathrm{Ni}(\mathrm{Ni} / \mathrm{Pd}, \mathrm{Ni} / \mathrm{Ag} / \mathrm{Pd})$ and $\mathrm{rGO}$ hybrid samples have been successfully prepared by a hydrothermal reaction using HMTA as capping agent and hydroxide source followed with in-situ reduction by heat treatment with $\mathrm{H}_{2}$ flow. Metallic $\mathrm{Ni}$ and its $\mathrm{Ni} / \mathrm{Pd}$ and $\mathrm{Ni} / \mathrm{Ag} / \mathrm{Pd}$ nanoparticles with diameter varying from $\sim 10-110 \mathrm{~nm}$ were well dispersed on reduced graphene oxide sheets. The $\mathrm{Ni} / \mathrm{Pd} / \mathrm{rGO}$ sample showed the best hydrogen uptake capacity of $0.13 \mathrm{wt} \%$ at room temperature $(295.15 \mathrm{~K})$ and atmospheric pressure (800 $\mathrm{mmHg}$ ) while the $\mathrm{Ni} / \mathrm{Ag} / \mathrm{Pd} / \mathrm{rGO}$ had the best hydrogen adsorption-desorption reversibility. The promising results encourage further studies with the replacement of $\mathrm{Pd}$ by Ni mixtures/alloys for hydrogen storage through spillover in ambient environment. 


\section{Acknowledgement}

The authors thank the support from the U.S. Air Force Office of Scientific Research (award \#FA9550-12-1-0159) and the National Science Foundation under DMR grant (\#0934157, PREM-UTPA/UMN-Science and Engineering of Polymeric and Nanoparticle-based Materials for Electronic and Structural Applications).

\section{Reference}

[1] Eberle U, Felderhoff M, Schuth F. Chemical and physical solutions for hydrogen storage. Angew Chem Int Ed Engl. 2009;48:6608-30.

[2] Heine T, Zhechkov L, Seifert G. Hydrogen storage by physisorption on nanostructured graphite platelets. Physical Chemistry Chemical Physics. 2004;6:980.

[3] Barbara Panella MH. Hydrogen physisorption in metal-organic porous crystals. Adv Mater. 2005;17:538-41.

[4] Suh MP, Park HJ, Prasad TK, Lim DW. Hydrogen storage in metal-organic frameworks. Chemical Reviews. 2012;112:782-835.

[5] M. Rzepka, P. Lamp. Physisorption of hydrogen on microporous carbon and carbon nanotubes. Journal of Physical Chemistry. 1998;102:10894-8.

[6] Borislav Bogdanovic MF, Stefan Kaskel. Improved hydrogen storage properties of Ti-doped sodium alanate using titanium nanoparticles as doping agents. Adv Mater. 2003;15:1012-5.

[7] Maximilian Fichtner OF, Oliver Kircher, Jorg Rothe. Small Ti clusters for catalysis of hydrogen exchange in $\mathrm{NaAlH}_{4}$. Nanotechnology. 2003;14:778-85.

[8] Xia Y, Yang Z, Zhu Y. Porous carbon-based materials for hydrogen storage: advancement and challenges. Journal of Materials Chemistry A. 2013;1:9365.

[9] Li Y, Ralph T. Yang. Hydrogen storage in metal-organic frameworks by bridged hydrogen spillover. Journal of American Chemical Society. 2006;128:8136-7.

[10] Anthony J Lachawiec J, Gongshin Qi, and Ralph T. Yang. Hydrogen storage in nanostructured carbons by spillover: bridge-building enhancement. Langmuir. 2005;21:11418-24.

[11] Lueking A. Hydrogen spillover to enhance hydrogen storage - study of the effect of carbon physicochemical properties. Applied Catalysis A: General. 2004;265:259-68.

[12] Lin Y, Ding F, Yakobson BI. Hydrogen storage by spillover on graphene as a phase nucleation process. Physical Review B. 2008;78.

[13] Chen G, Wang F, Liu F, Zhang X. One-pot preparation of Ni-graphene hybrids with enhanced catalytic performance. Applied Surface Science. 2014;316:568-74.

[14] Phan D-T, Chung G-S. A novel nanoporous Pd-graphene hybrid synthesized by a facile and rapid process for hydrogen detection. Sensors and Actuators B: Chemical. 2015;210:661-8.

[15] Li Q, Mahmood N, Zhu J, Hou Y, Sun S. Graphene and its composites with nanoparticles for electrochemical energy applications. Nano Today. 2014;9:668-83.

[16] Wu H, Wexler D, Liu H. Effect of different reductants for palladium loading on hydrogen storage capacity of double-walled carbon nanotubes. International Journal of Hydrogen Energy. 2011;36:9032-6.

[17] Hui-Ming Cheng Q-HY, Chang Liu. Hydrogen storage in carbon nanotubes. Carbon. 2001;39:1447-54. 
[18] Xia K, Hu J, Jiang J. Enhanced room-temperature hydrogen storage in super-activated carbons: The role of porosity development by activation. Applied Surface Science. 2014;315:261-7.

[19] Texier-Mandoki N, Dentzer J, Piquero T, Saadallah S, David P, Vix-Guterl C. Hydrogen storage in activated carbon materials: Role of the nanoporous texture. Carbon. 2004;42:27447.

[20] Huanlei Wang QG, Juan Hu. High hydrogen storage capacity of porous carbons prepared by using activated carbon. Journal of American Chemical Society. 2009;131:7016-22.

[21] Tellez-Juárez MC, Fierro V, Zhao W, Fernández-Huerta N, Izquierdo MT, Reguera E, et al. Hydrogen storage in activated carbons produced from coals of different ranks: Effect of oxygen content. International Journal of Hydrogen Energy. 2014;39:4996-5002.

[22] Guo CX, Wang Y, Li CM. Hierarchical graphene-based material for over 4.0wt\% physisorption hydrogen storage capacity. ACS Sustainable Chemistry \& Engineering. 2012:120928163241005.

[23] Adams BD, Chen A. The role of palladium in a hydrogen economy. Materials Today. 2011;14:282-9.

[24] Huang C-C, Pu N-W, Wang C-A, Huang J-C, Sung Y, Ger M-D. Hydrogen storage in graphene decorated with $\mathrm{Pd}$ and $\mathrm{Pt}$ nano-particles using an electroless deposition technique. Separation and Purification Technology. 2011;82:210-5.

[25] Zhu J, Cheng J, Dailly A, Cai M, Beckner M, Shen PK. One-pot synthesis of Pd nanoparticles on ultrahigh surface area $3 \mathrm{D}$ porous carbon as hydrogen storage materials. International Journal of Hydrogen Energy. 2014;39:14843-50.

[26] Tierney HL, Baber AE, Kitchin JR, Sykes ECH. Hydrogen dissociation and spillover on individual isolated palladium atoms. Physical Review Letters. 2009;103.

[27] Dibandjo P, Zlotea C, Gadiou R, Matei Ghimbeu C, Cuevas F, Latroche M, et al. Hydrogen storage in hybrid nanostructured carbon/palladium materials: Influence of particle size and surface chemistry. International Journal of Hydrogen Energy. 2013;38:952-65.

[28] Chen C-H, Chung T-Y, Shen C-C, Yu M-S, Tsao C-S, Shi G-N, et al. Hydrogen storage performance in palladium-doped graphene/carbon composites. International Journal of Hydrogen Energy. 2013;38:3681-8.

[29] Bhowmik K, Mukherjee A, Mishra MK, De G. Stable Ni nanoparticle-reduced graphene oxide composites for the reduction of highly toxic aqueous $\mathrm{Cr}(\mathrm{VI})$ at room temperature. Langmuir. 2014;30:3209-16.

[30] Huang TC, Wei MC, Chen HI. Preparation of hydrogen-permselective palladium-silver alloy composite membranes by electroless co-deposition. Separation and Purification Technology. 2003:32:239-245.

[31] Isaac Childres LAJ, Wonjun Park, Helin Cao, Yong P. Chen. Raman Spectroscopy of Graphene and Related Materials.

[32] Zhou Y, Bao Q, Tang LAL, Zhong Y, Loh KP. Hydrothermal dehydration for the "green" reduction of exfoliated graphene oxide to graphene and demonstration of tunable optical limiting properties. Chemistry of Materials. 2009;21:2950-6.

[33] Zhu Y, Murali S, Cai W, Li X, Suk JW, Potts JR, et al. Graphene and graphene oxide: synthesis, properties, and applications. Adv Mater. 2010;22:3906-24.

[34] Lucchese MM, Stavale F, Ferreira EM, Vilani C, Moutinho M, Capaz RB, et al. Quantifying ion-induced defects and Raman relaxation length in graphene. Carbon. 2010;48:1592-7.

[35] Chen G, Wang F, Liu F, Zhang X. One-pot preparation of Ni-graphene hybrids with enhanced catalytic performance. Applied Surface Science. 2014;316:568-74.

[36] Dreyer DR, Park S, Bielawski CW, Ruoff RS. The chemistry of graphene oxide. Chem Soc Rev. 2010;39:228-40. 
[37] Ji Z, Shen X, Zhu G, Zhou H, Yuan A. Reduced graphene oxide/nickel nanocomposites: facile synthesis, magnetic and catalytic properties. Journal of Materials Chemistry. 2012;22:3471.

[38] Khalfaoui M, Knani S, Hachicha MA, Lamine AB. New theoretical expressions for the five adsorption type isotherms classified by BET based on statistical physics treatment. Journal of Colloid and Interface Science. 2003;263:350-6.

[39] Yamauchi M, Kobayashi H, Kitagawa H. Hydrogen storage mediated by $\mathrm{Pd}$ and $\mathrm{Pt}$ nanoparticles. Chemphyschem. 2009;10:2566-76.

[40] Antolini E, Formation of carbon-supported PtM alloys for low temperature fuel cells: a review. Materials Chemistry and Physics. 2003:78:563-573.

[41] Schlapbach L, Züttel A. Hydrogen-storage materials for mobile applications. Nature. 2001:414:353-358. 


\section{Graphic Abstract:}

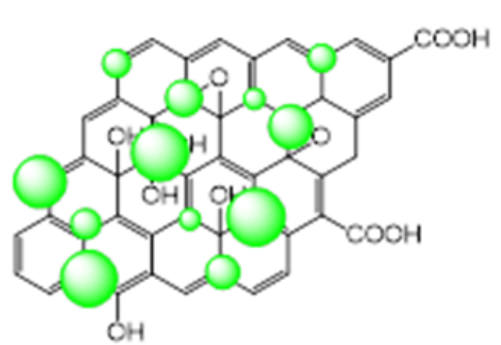

Ni(Ni/Pd, Ni/Ag/Pd)/rGo

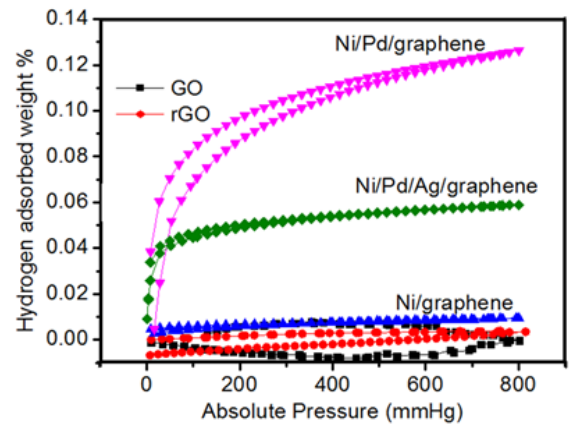

